\title{
Global pseudo-atrial flutter ECG appearance secondary to unilateral parkinsonian tremor
}

\author{
Michael Chi Yuan Nam, Laura Best, Kim Greaves, Naresh Dayananda
}

Sunshine Coast Hospitals and Health Service, Nambour, Queensland, Australia

\section{Correspondence to} Dr Michael Chi Yuan Nam, dr.michael.nam@gmail.com

Accepted 6 January 2016
CrossMark

To cite: Nam MCY, Best $L$, Greaves K, et al. BMJ Case Rep Published online: [please include Day Month Year] doi:10.1136/bcr-2015214048

\section{DESCRIPTION}

An 82-year-old man with previous bioprosthetic aortic valve replacement for aortic stenosis had a routine ECG (figure 1). This was thought to represent an atrial tachycardia with cycle length $280 \mathrm{~ms}$ and 3:1 atrioventricular response. A diagnosis of atrial flutter was made based on tachycardia cycle length, p-wave morphology and previous cardiac surgery. He had a mild left-sided tremor in keeping with known Parkinson's disease. The patient was anticoagulated and admitted electively for an electrophysiology (EP) study. In the EP laboratory, the patient had a 12-lead ECG (figure 2A) showing sinus rhythm with a ventricular rate of $60 \mathrm{bpm}$.
Figure $2 \mathrm{~B}$ shows the EP electrogram recorded in the coronary sinus confirming sinus rhythm. However, it was noted that the 'flutter waves' in the original ECG were most marked in the left limb leads. In the EP laboratory, ECG labels are placed on the torso, as opposed to the limbs. After moving ECG labels to the forearms, the surface ECG is shown (figure 3) with re-emergence of 'flutter' waves. A diagnosis of pseudo-atrial flutter was made.

Parkinsonian tremor characterised by a $5 \mathrm{~Hz}$ upper-limb dyskinesia can result in a pseudo p-wave artefact on ECG at a rate of $300 \mathrm{bpm}$, mimicking atrial flutter. ${ }^{1} 2$ However, pseudo p-waves are usually only seen in the limb leads. We
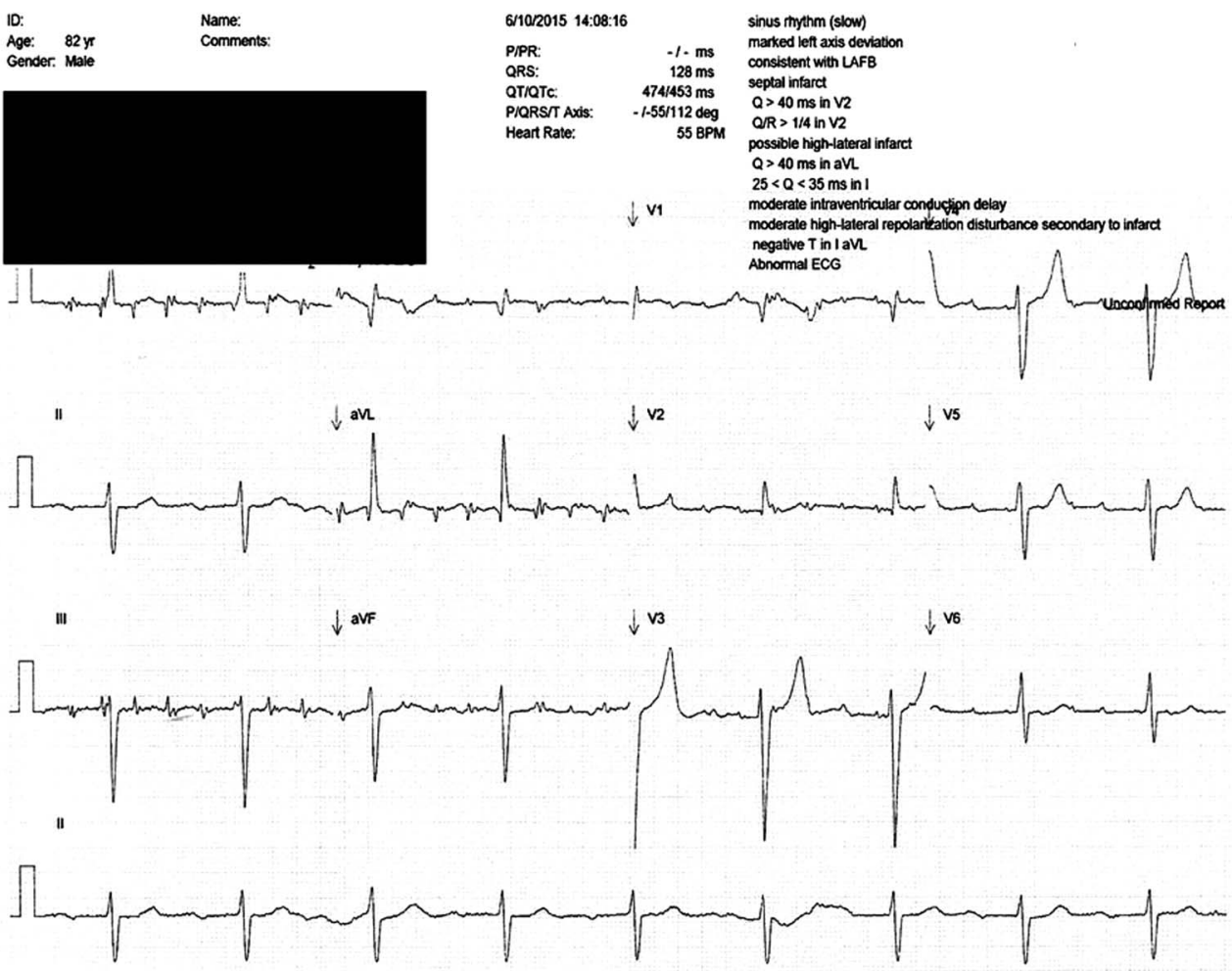

Figure 1 Twelve-lead ECG showing apparent atrial tachycardia with atrial rate of 200/min, leftward axis deviation and ventricular rate of $55 \mathrm{bpm}$. 


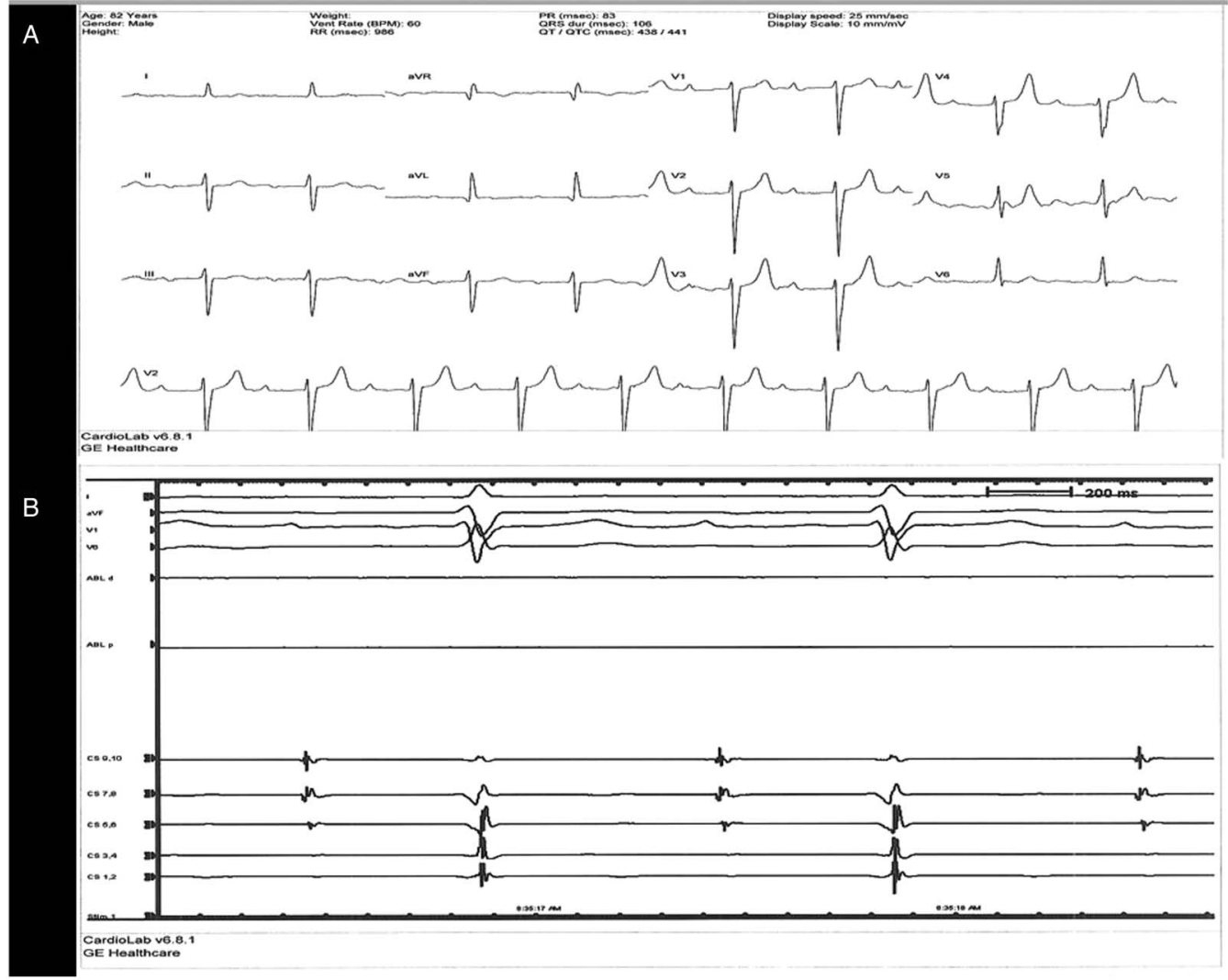

Figure 2 (A) Twelve-lead ECG performed in EP laboratory showing normal sinus rhythm with first-degree heart block, left axis deviation and ventricular rate of $60 \mathrm{bpm}$. (B) EP CardioLab (GE Healthcare) printout during EP study showing surface ECG on top, and corresponding coronary sinus electrogram below. Surface ECG p-wave and QRS correspond to electrogram A-wave and V-wave, respectively. This confirms sinus rhythm.

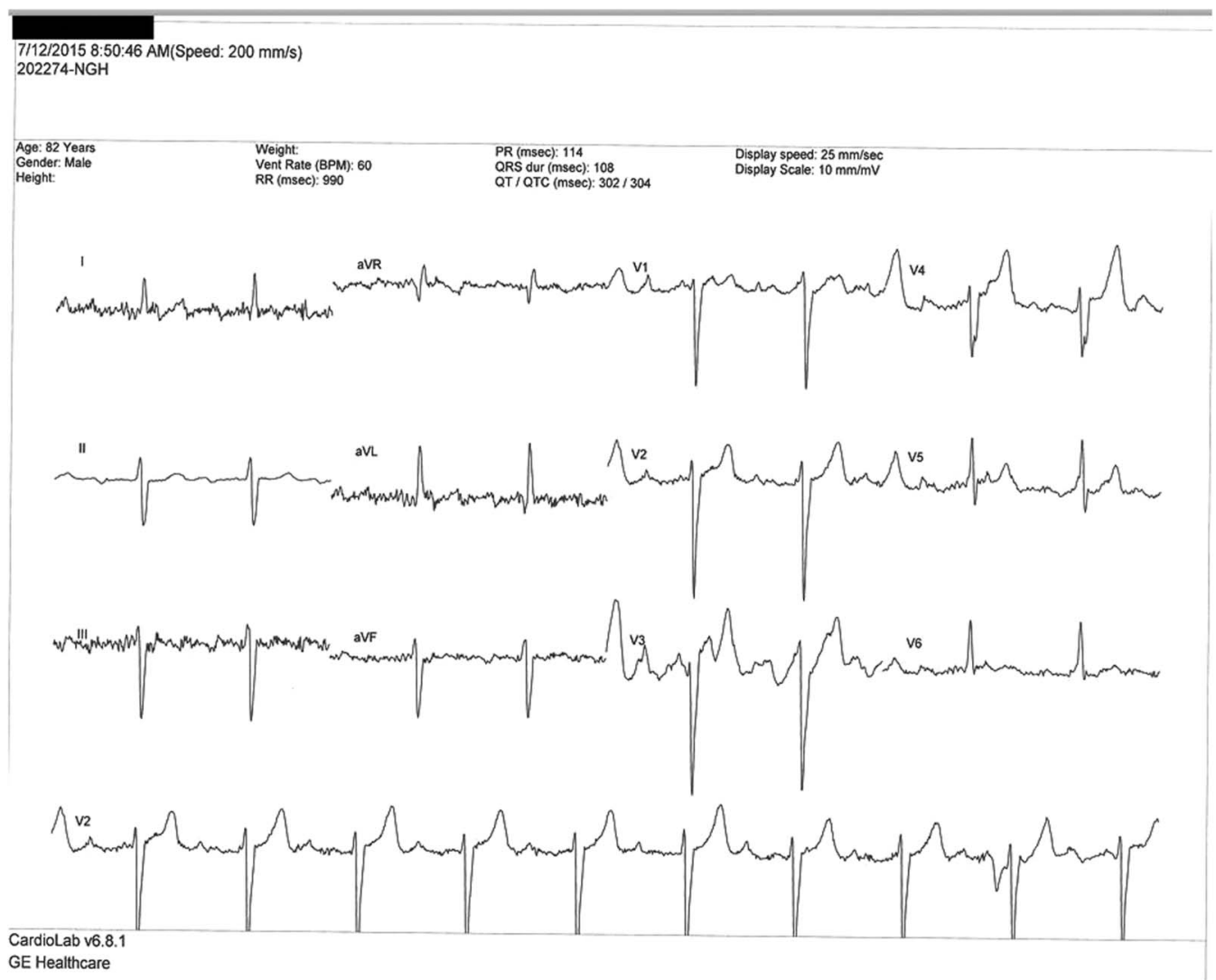

Figure 3 Twelve-lead ECG repeated. On moving limb leads from torso to limbs, pseudo-flutter waves reappear globally on surface ECG. 
demonstrate that tremor-induced flutter waves can result in global p-wave changes in left-sided tremor. This may be

\section{Learning points}

- Pseudo-atrial flutter secondary to parkinsonian tremor can present with precordial flutter waves, and not exclusively in limb leads.

- This finding highlights the importance of ECG interpretation within the clinical context.

- Always consider movement artefact in ECG diagnosis of atrial tachycardias to avoid incorrect diagnosis and subsequent unnecessary treatment. because, predominantly, the left limbs form the negative composite pole of the precordial ECG waveform, and hence leftsided tremors would alter its morphology. ${ }^{3}$

Competing interests None declared.

Patient consent Obtained.

Provenance and peer review Not commissioned; externally peer reviewed.

\section{REFERENCES}

1 Hwang WJ, Chen JY, Sung PS, et al. Parkinsonian tremor-induced electrocardiographic artifacts mimicking atrial flutter/fibrillation or ventricular tachycardia. Int I Cardiol 2014;173:597-600.

2 Barrett CD, Kelly PJ, Halley C, et al. Pseudo atrial flutter. Eur J Intern Med 2007;18:603-4.

3 Bacharova L, Selvester RH, Engblom $\mathrm{H}$, et al. Where is the central terminal located? In search of understanding the use of the Wilson central terminal for production of 9 of the standard 12 electrocardiogram leads. J Electrocardiol 2005;38:119-27.

Copyright 2016 BMJ Publishing Group. All rights reserved. For permission to reuse any of this content visit http://group.bmj.com/group/rights-licensing/permissions.

BMJ Case Report Fellows may re-use this article for personal use and teaching without any further permission.

Become a Fellow of BMJ Case Reports today and you can:

- Submit as many cases as you like

- Enjoy fast sympathetic peer review and rapid publication of accepted articles

- Access all the published articles

- Re-use any of the published material for personal use and teaching without further permission

For information on Institutional Fellowships contact consortiasales@bmjgroup.com

Visit casereports.bmj.com for more articles like this and to become a Fellow 